\title{
A Low Cost Water Meter System based on the Global System for Mobile Communications
}

\author{
Peter Mwangi \\ Department of Physics \\ Kenyatta University, PO BOX \\ 43844, Nairobi, Kenya
}

\author{
Elijah Mwangi \\ School of Engineering \\ University of Nairobi, PO BOX \\ 30197, Nairobi, Kenya
}

\author{
Patrick M. Karimi \\ Institute of Energy Studies and \\ Research \\ Kenya Power, PO BOX 30099 \\ Nairobi, Kenya
}

\begin{abstract}
The accurate reading of a customer water-meter is important as it is the main revenue base for the water authorities. The traditional data collection process is still common in developing countries despite the inherent inefficiency, inaccuracy and labour intensity. A solution to improvement could be based on sensor and communication technology. In this research an automatic water meter reading system has been designed, fabricated and tested. It consists of G1/2 flow sensor, PIC18F4550 microcontroller, LCD, GSM module and solenoid control valve. When water flows through flow sensor, pulses are generated which are converted to volumetric flow using PIC18F550.The LCD displays the readings which are sent automatically to the Water Company as an SMS for billing purposes after a specified period. The proposed system is cost effective and gives automated water meter reading at high accuracy.
\end{abstract}

\section{Keywords}

PIC18F4550 microcontroller, GSM module, sensor, LCD display.

\section{INTRODUCTION}

In many parts of the world analogue water meters have been installed by water companies to measure the consumer's water consumption. These water meters are read on a monthly basis by an authorized employee and the consumer's bill is computed based on the approved rates according to the amount of water consumed. Sometimes the customer premises are not easily accessible and consumption estimates have to be used in computation of the water bill. This is error prone as accuracy cannot be guaranteed. This method of manual data collecting is also expensive, labour intensive and hence inefficient.

There are several ways in which meter reading can be accomplished. The most common are; direct reading, remote reading, touch read and automatic meter reading.

\section{i) Direct reading}

This is where an individual directly reads the meter register. The reading is entered manually in a log-book.

\section{ii) Remote reading}

This is where reading is done through an electronic signal, usually with a wire to a separate station where the individual could either direct read or touch read.

\section{iii) Touch read or plug-in reader}

This is where a handheld device is used. The device picks the electronic signal from plugging-in or touching the remote station and translates it into the number of cubic meters consumed. The remote station can even be on top of the meter pit lid. The readings are stored on the hand-held device until the meter reader gets back to the office to be downloaded to a computer.

\section{iv) Automatic meter reading}

Automatic Meter Reading System (AMR) is the remote collection of consumption data from customers' utility like energy meters, water meters among others using radio frequency, telephony, power-line or satellite communications technologies and process the data to generate the bill [12].

There are various researchers who have provided solutions to automate water consumption data collection. However, little or no attention has been paid to the issue of using GSM network to continuously update the utility company on consumption of water.

The proposed system seeks to pay more attention on the use of GSM network to update the water utility company on water consumption.

The rest of this paper has been organized as follows. In section 2, a brief presentation of water flow measurement has been given. In section 3 a brief description of the proposed system has been given. The results and discussions have been presented in section 4 . In section 5 a conclusion of the investigations and suggestions for further work have been given.

\section{WATER FLOW MEASUREMENT}

There are two basis of measuring flow, these are volumetric basis and weight basis. The basic relationship for determining the liquid's flow in a pipe is given by the product of cross sectional area of the pipe and the average velocity of the flow. The other factors that affect liquid flow rate include the liquid's viscosity, density and the friction of the liquid in contact with the pipe [15].

Water meters generally fall into one of these three categories: simple mechanical water meters, mechanical water meters with an electronic communication device, and fully electronic water meters.

One of the popular water flow measurement techniques is the velocity type In this research a turbine type meter which is a velocity-based meter has been employed. In this meter the entire fluid to be measured enters the flow meter, then passes through a rotor. The flowing fluid impinges on the blades of turbine and imparts a force that causes the rotation of the rotor. At the steady state, the speed of the rotor is directly proportional to the fluid velocity, and hence to volumetric flow rate. The speed of rotation is monitored in most of the

meters by a magnetic pick-up coil which is fitted to the outside of the meter housing. The pick-up coil consists of a permanent magnet with coil windings which are mounted in close proximity to the rotor but external to the fluid channel. As each rotor blade passes the magnetic pick-up coil, it generates a voltage pulse which is a measure of the flow rate, and the total number of pulses gives a measure of the total 
flow. By digital techniques, the electrical voltage pulses can be computed [14]. The number of pulses per unit volume, $n_{p}$ is given by

$$
n_{p}=\frac{T_{p} f}{Q}
$$

Where

$T_{p}=$ time constant in minutes

$Q=$ Volumetric flow rate

$f=$ frequency

\section{THE PROPOSED SYSTEM}

The proposed water meter system seeks to automate water meter reading by sending a short message to the Utility Company after a specified period. It can solve the challenges the other water meters have posed over a period of time especially in terms of accuracy, cost and efficiency. The system is made up of two parts; these are the hardware and the software components.

\subsection{Hardware Components}

In the proposed system the hardware parts consists of a G1/2 flow sensor, a PIC18F4550 Microcontroller, an LCD, a valve controller, a power supply and a GSM module.
When water valve is opened, water passes through the rotor of the G1/2 flow sensor, causing it to rotate at the speed equivalent to velocity of flow. The rotor speed changes in relationship to the rate of flow of water. As each blade passes through the magnet, a magnetic field is created at the base of the Hall sensor and thus pulses are generated. The pulses are counted and then converted to volumetric flow using PIC18F4550. This volumetric flow is the same as the consumption. The volume consumed is displayed on an LCD and is automatically sent after a specified period through the GSM network. The block diagram of the main parts of the proposed system is illustrated in fig 1 . It consists of a flow sensor where pulses are generated, PIC18F4550 Microcontroller which converts the pulses into volumetric flow, an LCD to display the volume and a GSM module to transmit the volume measured to a utility company.

\subsection{Programme code development}

The programme code has been written as a text file using the Mikroc Integrated Development platform. The resulting hex file is then downloaded into the PIC18F4550 program memory using the PICkit2 programmer. A flow chart of the proposed design is presented in fig 2

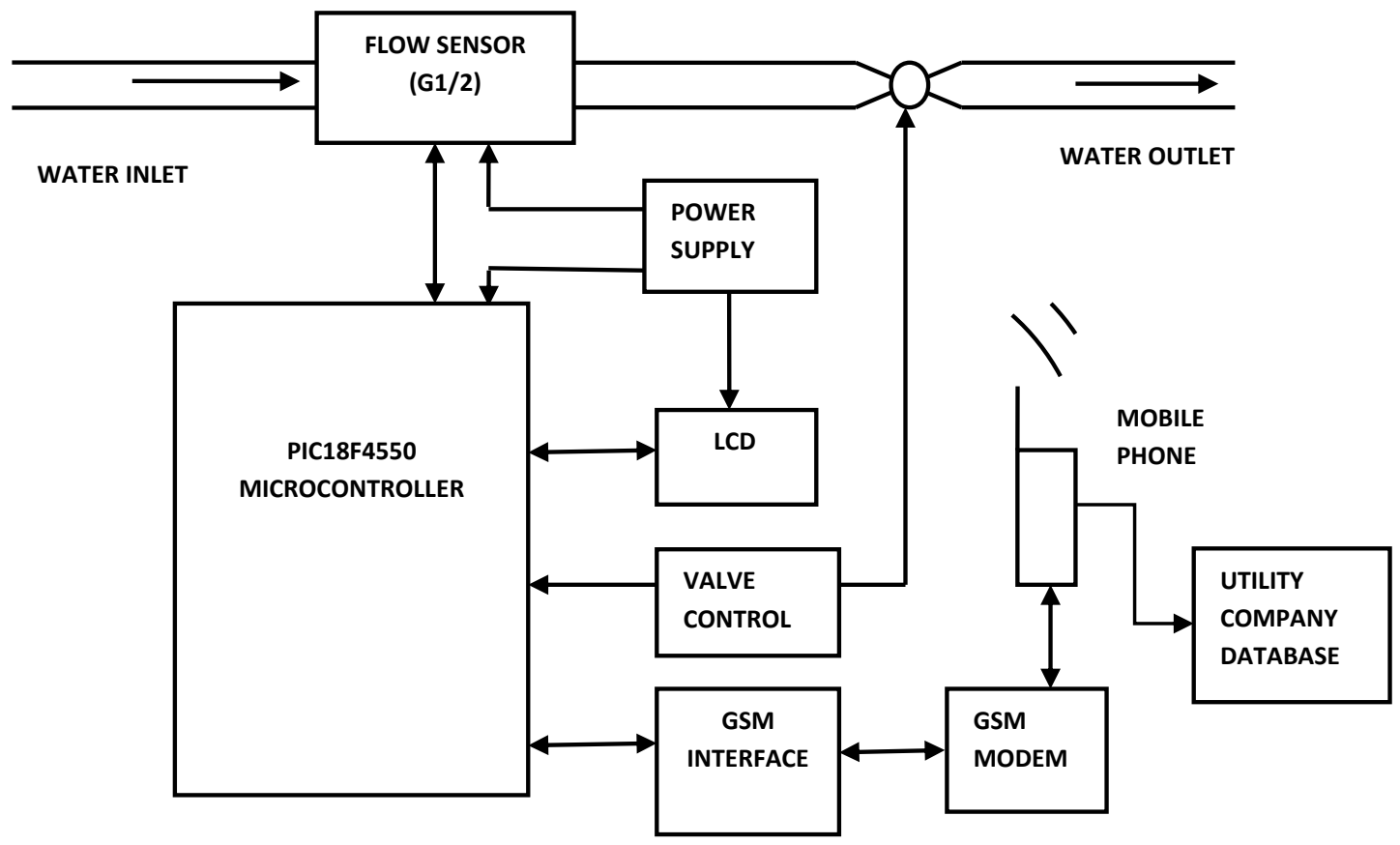

Fig 1: Block diagram of the proposed intelligent water meter system 


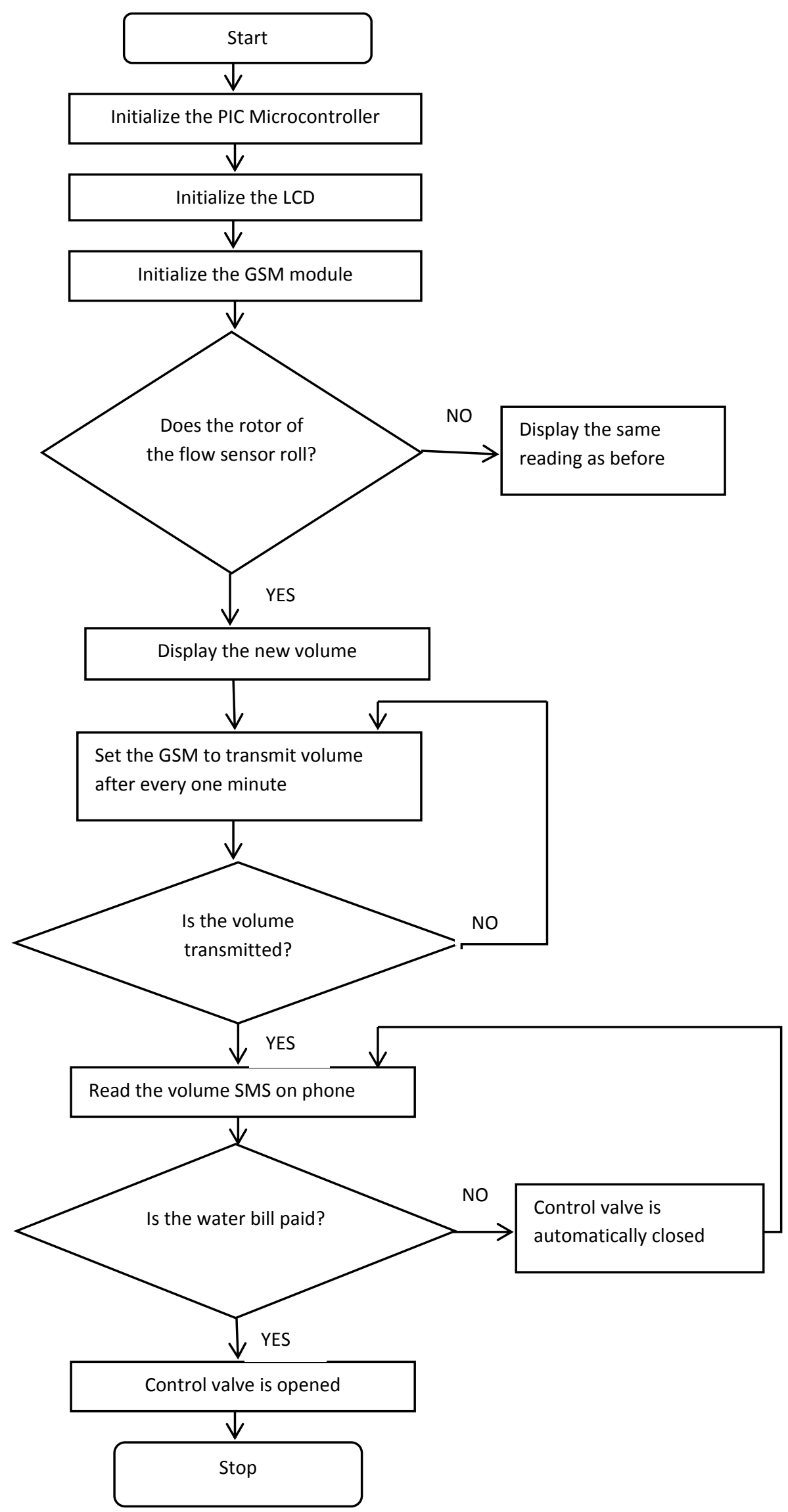

Fig 2: Flow chart for the system software design 


\section{RESULTS AND DISCUSSIONS}

\subsection{Flow rate calculation}

To test the proposed system, water has been allowed to flow at different rates. To read flow rate at various frequencies, a $\mathrm{C}$ program has been written. As water flows at different frequencies, the time taken to fill a 1 litre container has been recorded. A water valve has been used during this test to control the amount of water flowing. It is opened at different intervals but in an increasing manner. When opened, the frequency when the least amount of water was flowing was found to be $6 \mathrm{~Hz}$. The maximum frequency when the valve was completely opened was found to be $66 \mathrm{~Hz}$. The relationship between Frequency in $\mathrm{Hz}$ and Time (in sec) taken to fill 1 litre is shown in table

Table 1: Time taken to fill $1 \mathrm{~L}$ at different frequencies and the resulting flow rate

\begin{tabular}{|c|l|l|}
\hline $\begin{array}{l}\text { Frequency } \\
(\mathrm{Hz})\end{array}$ & $\begin{array}{l}\text { Time } \\
(\mathrm{Sec})\end{array}$ & $\begin{array}{l}\text { Flow rate } \\
(\text { litres/min })\end{array}$ \\
\hline 6 & 76 & 0.8 \\
\hline 12 & 39 & 1.5 \\
\hline 18 & 24 & 2.5 \\
\hline 24 & 20 & 3 \\
\hline 30 & 17 & 3.5 \\
\hline 36 & 13 & 4.6 \\
\hline 42 & 11 & 5.5 \\
\hline 48 & 10 & 6 \\
\hline 54 & 9 & 6.7 \\
\hline 60 & 8 & 7.5 \\
\hline 66 & 7 & 8.6 \\
\hline
\end{tabular}

From Table 1 the flow rate at each of the frequencies can be computed and is given in litres/minute. A graph of flow rate in litres/min against Frequency $(\mathrm{Hz})$ is illustrated in Fig 3.

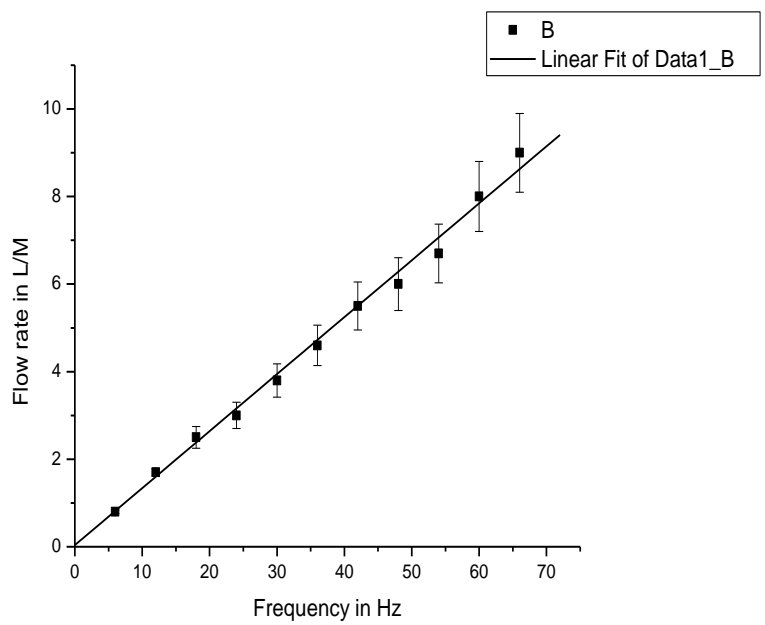

Fig 3: Frequency variation with flow rate

The graph is of the form $\mathrm{Y}=\mathrm{A}+\mathrm{B} * \mathrm{X}$. The values of $\mathrm{A}$ and $\mathrm{B}$ are shown in table 2 .
Table 2: Data analysis

\begin{tabular}{|c|c|c|}
\hline Parameter & Value & Error \\
\hline A & -0.02157 & 0.09336 \\
\hline B & 0.13204 & 0.00587 \\
\hline $\mathrm{R}$ & SD & \\
\hline 0.99609 & 0.66527 & \\
\hline
\end{tabular}

From table 2, a factor equivalent to the gradient has been determined to be 0.13 . Using this factor, any flow rate in litres/min can be obtained as follows;

Flow rate in litres $/ \mathrm{min}=0.13$ (frequency in $\mathrm{Hz}$ )

The volume can be computed by multiplying the flow rate and time. To determine cumulative quantity of water over a unit period, a programme code has been written and burned in the PIC18F4550.

\subsection{The GSM Module}

The GSM module SIM900 has been employed in the investigations presented in this paper. The module communicates with the microcontroller and mobile phone through the UART port. The SIM900 is a Quad-band GSM/GPRS. It works on the frequencies; $850 \mathrm{MHz}, 900$ $\mathrm{MHz}, 1800 \mathrm{MHz}$ and $1900 \mathrm{MHz}$.

An experimental investigation has been carried out on the GSM transmission and the readings have been recorded as shown on table 3. For example, in the first row of table 3, when water valve is not opened no water flows and as such the reading displayed and transmitted will be zero litres. The rest of the rows show the readings displayed and transmitted through the GSM network after every 30 seconds. Where readings are similar for instance in row 5 and 6 , no water is being used at that instance.

Table 3: LCD and GSM readings

\begin{tabular}{|l|l|l|}
\hline $\begin{array}{l}\text { Trials } \\
\text { Minutes) }\end{array}$ & $\begin{array}{l}\text { LCD Reading } \\
\text { in (Litres) }\end{array}$ & $\begin{array}{l}\text { Reading via GSM in } \\
\text { (Litres) }\end{array}$ \\
\hline 0.5 & 0 & 0 \\
\hline 1 & 2 & 2 \\
\hline 1.5 & 4 & 4 \\
\hline 2 & 6 & 6 \\
\hline 2.5 & 8 & 8 \\
\hline 3 & 8 & 8 \\
\hline 3.5 & 11 & 11 \\
\hline 4 & 12 & 12 \\
\hline 4.5 & 12 & 12 \\
\hline 5 & 14 & 14 \\
\hline 5.5 & 14 & 14 \\
\hline 6 & 15 & 15 \\
\hline 6.5 & 17 & 17 \\
\hline 7 & 17 & 17 \\
\hline 7.5 & 18 & 18 \\
\hline 8 & 19 & 19 \\
\hline 8.5 & 19 & 19 \\
\hline 9 & 20 & 20 \\
\hline
\end{tabular}

\subsection{Control valve}

A solenoid valve gravity feed has been used in this research. This is a valve that opens or closes to either allow water to 
pass through or prevent water from flowing. The opening and closing of the valve is under the control of water supply utility. It gives access to water for authorized customers who are in good standing in terms of service payments. The valve control mechanism is through a short message.

A test has been carried out to test the valve opening and closing mechanism through short messages. The valve opens any time a short message is sent to open it and closes any time a message is sent to close it.

\subsection{Testing the system}

The entire system has been tested against a measuring cylinder. Table 4 shows the volume obtained from the proposed design compared to the actual volume. The results have been obtained from twenty trials.

Table 4: Measured volume of the proposed design versus the actual volume

\begin{tabular}{|c|c|l|c|}
\hline Trials & $\begin{array}{l}\text { Actual } \\
\text { Volume in } \\
\text { L }\end{array}$ & $\begin{array}{l}\text { Volume in L } \\
\text { displayed by } \\
\text { designed meter }\end{array}$ & $\begin{array}{l}\text { Percentage } \\
\text { error (\%) }\end{array}$ \\
\hline 1 & 1 & 1.02 & 2 \\
\hline 2 & 1 & 1.00 & 0 \\
\hline 3 & 1 & 0.99 & 1 \\
\hline 4 & 1 & 1.01 & 1 \\
\hline 5 & 1 & 1.02 & 2 \\
\hline 6 & 1 & 1.02 & 2 \\
\hline 7 & 1 & 1.00 & 0 \\
\hline 8 & 1 & 0.98 & 2 \\
\hline 9 & 1 & 1.00 & 0 \\
\hline 10 & 1 & 1.01 & 2 \\
\hline 11 & 1 & 1.02 & 0 \\
\hline 12 & 1 & 1.00 & 2 \\
\hline 13 & 1 & 0.98 & 0 \\
\hline 14 & 1 & 1.00 & 1 \\
\hline 15 & 1 & 0.99 & 2 \\
\hline 16 & 1 & 1.02 & 0 \\
\hline 17 & 1 & 1.00 & 1 \\
\hline 18 & 1 & 0.99 & 1 \\
\hline 19 & 1 & 0.99 & 0 \\
\hline 20 & 1 & 1.00 & \\
\hline
\end{tabular}

From table 3 the average error was computed and found to be $1.00 \%$.

Comparison between the actual value and the designed meter value

1.05

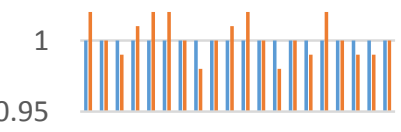

- AqtuahVałueio L13 1 (Desggned meter value in L

Fig 4: Comparison between actual value and measured value by the designed meter

\section{CONCLUSION}

A low cost GSM based water meter system has been designed and implemented. The system has integrated a G1/2 flow sensor, a Liquid Crystal Display, a PIC18F4550 microcontroller and a solenoid valve. The Mikroc Integrated Development Environment has been used to write, develop and debug codes for the PIC18F4550. The designed system has managed to read flow rate and based on the code stored in the microcontroller's program memory, calculated the volume in litres with an average error of about $1 \%$. The volume is displayed on the LCD and also transmitted to a mobile phone through GSM Network. The system is effective and hence can be used in water meter industry to automate water meter reading hence saving on cost and man hours.

The proposed system can be extended to enhance monitoring of water usage by the utility company. This would require individual consumers be provided with the proposed system while another system is used to monitor whether the total volumes of each of the individual meter system matches the total volume supplied by the utility company. This would help in detecting water losses due to leakages.

\section{REFERENCES}

[1] Zhao, H., Guo, L., Wang, W. (2015). Research on wireless meter reading technology applied in ultrasonic water meter based on Zigbee. Indian Journal of research 4: 47-50.

[2] Nelson, S. (2014). A non-contact arrow pointer sensor design to reduce power consumption of low cost and high accuracy hybrid water meter.Proceedings of IEEE Sensors Journal3: 558-565.

[3] Kolhare, N.R. and Thorat, P.R. (2013).An Approach of Flow Measurement in Solar Water Heater Using Turbine Flow Meter. International Journal of Engineering Research and Technology2: 1-4

[4] Hsia, S.C. Sheu, M.H. and Chang, Y.G. (2013). Arrow Pointer Sensor Design for Low Cost Water Meter. Proceedings of IEEE sensors journal13:1281-1287

[5] Trivedi, P. (2013).PIC 18 Peripheral Interface Controller. International Journal of Innovative Research in Science, Engineering and Technology 2:1804-1809

[6] Benzi, F., Anglani, N., Bassi, E. and Frosini, L. (2011). Electricity smart meters interface for the households. IEEE Transactions on Industrial Electronics58: 44874494

[7] Quan, X.L. and Gang, L. (2010). Design of remote automatic meter reading system based on ZigBee and GPRS. Proceedings of the Third International Symposium, Jiaozuo, China 10: 186-189.

[8] Vinu, V.D. (2009). Wireless Communication System for Energy Meter Reading. International Conference on Advances in Recent Technologies in Communication and Computing Voltage Apparatus. Beijing 9: 1-9.

[9] Beil J. (1996). Choosing a microcontroller Electronic product design: Newness. Oxford.

[10] Jinsoo H., Intark H. and Kwang-Roh P. (2008). Zigbeebased IR Remote Control Repeater and its control Message frame format, Proceedings of the 2008 International Symposium on Consumer electronics, Algarve, Portugal 57. IEEE Conference Publications: 14.

[11] Ayala, K.J. (1998). 8085 Microcontroller, Architecture, Programming and Applications, 2nd edition, Penram International Publishing (India), Mumbai.

[12] Moghavvemi, S.Y. and Wong, S. K. (2005).A reliable and economically feasible automatic meter reading system using power line distribution network 
International Journal of Engineering -Materials and Energy Research Center 18: 301-318.

[13] Meiklejohn, D. (2008). Introduction to PIC Programming.http://www.gooligum.com downloaded in February 2014.

[14] Rob, K. and Gabor, M. (2010). A Perspective on RadioFrequency Exposure Associated With Residential Automatic Meter Reading Technology. California, USA: Electrical Power Research Institute. California.

[15] Mulley, R (2004). Flow of Industrial Fluids: Theory and Equations. USA: CRC Press.
[16] Mouly, M. and Pautet, M.B. (2002). The GSM System for Mobile Communications. Leland Scott Bloebaum, USA: Telecom Publishing.

[17] Bates M. (2008).Programming 8-bit PIC Microcontrollers in $\mathrm{C}$ with Interactive Hardware Simulation: Newness. Oxford.

[18] Bates M. (2011). "PIC microcontrollers; An Introduction to Microelectronics": Newness. Oxford.

[19] Mohamed F., Mounir B. and Bedda M. (2008). Microcontroller based heart rate monitor. The International Arab Journal of Information Technology5:1-5. 